\title{
LA CARACTERÍSTICA DIFERENCIAL DE LOS HUMANOS EN PERSPECTIVA NOOLÓGICA
}

\author{
Jesús Conill \\ Universidad de Valencia ${ }^{1}$
}

Resumen: El objetivo del artículo es mostrar la contribución de la Noología de Zubiri para establecer la diferencia entre el hombre y el animal no humano. La noología consiste en una transformación de la fenomenología, que analiza el acto de la intelección sentiente, mediante la combinación del análisis filosófico y el conocimiento científico, llegando hasta una nueva metafísica de la realidad personal, que se funda en la inteligencia.

Palabras clave: Noología, Fenomenología, Persona, Inteligencia sentiente, Hiperformalización, Zubiri.

\section{The Human Differential Characteristic in Noologycal Perspective}

Abstract: The aim of this paper is to show the contribution of Zubiri's Noology for establishing the difference between human being and non human animals. Noology consists in a transformation of Phenomenology, which analyses the act

1 Este estudio se inserta en el Proyecto de Investigación Científica y Desarrollo Tecnológico FFI2016-76753-C2-1-P, financiado por el Ministerio de Economía y Competitividad, y en las actividades del grupo de investigación de excelencia PROMETEO de la Generalidad Valenciana. 
of the sentient intellection through a combination of philosophical analysis and scientific knowledge, in order to achieve a new metaphysics of personhood, based on the intelligence.

Keywords: Noology, Phenomenology, Personhood, Sentient Intelligence, Hyperformalization, Zubiri.

Recibido: 30/09/2017 Aprobado: 5/11/2017

Agradezco al Profesor Juan Arana y a la Fundación Tatiana Pérez de Guzmán la oportunidad que me brindan de participar en este Curso celebrado en su sede del Observatorio Activo de Ávila; y aprovecho la ocasión también para felicitar al profesor Arana por haber sabido crear este ámbito de pensamiento y reflexión tan cualificado y productivo ${ }^{1}$, reuniendo a profesores que forman parte del Seminario "Naturaleza y Libertad", provenientes de diversas Universidades, empezando por la de Sevilla.

En mi intervención expondré la contribución de la perspectiva noológica de Zubiri para establecer la diferencia entre el hombre y el animal no humano. En la filosofía de Zubiri cabrían otros enfoques como el metafísico y el antropológico, pero teniendo en cuenta el estado de la investigación de los estudios zubirianos me parece que conviene conceder la prioridad al enfoque

1 Véase sobre el tema que nos ocupa, por ejemplo, los recientes libros de Arana (2015), Rodríguez Valls (2017) y de Diéguez (2017). 
noológico ${ }^{2}$, aun cuando no se pueda —ni se deba - separar de las otras posibles perspectivas, porque, en último término, están intrínsecamente unidas. La aportación de Zubiri no se reduce a continuar la antropología filosófica con base biológica de finales del siglo XIX y primera parte del siglo XX (de la que tanto pudo aprender) ${ }^{3}$, ni se entrega a los reduccionismos de una presunta antropología científica, pero tampoco se limita a repetir los tópicos de la metafísica tradicional, ni se dejó seducir por los derroteros de la ontología heideggeriana, sino que constituye un camino diferente y propio, en el que se articulan de modo muy fecundo los conocimientos científicos de su época (genética y neurología) y una elaborada visión filosófica ${ }^{4}$.

\section{La perspectiva noológica zubiriana}

La Noología, expuesta en la trilogía zubiriana (o tríptico) [Inteligencia sentiente $^{5}$ (1980) Inteligencia y logos (1982) e Inteligencia y razón (1983)], fue fruto de un Seminario, en el que, según cuenta Diego Gracia, viernes tras

2 Vid., por ejemplo, Diego Gracia (2007) y (2017).

3 Son significativas las obras de Ernst Haeckel, Thomas Henry Huxley, Hermann Klaatsch, Max Scheler, Arnold Gehlen, Plessner, Portmann, vid. Gracia (2017, Parte III, capítulos 12, 13 y 14).

4 Curso "Ciencia y Filosofía", "Notas sobre la inteligencia humana", Sobre la esencia, Sobre el hombre, Estructura dinámica de la realidad, Inteligencia sentiente, El hombre y Dios, etc.

5 Este título del primer volumen fue cambiado luego por el de Inteligencia y realidad. 
Jesús Conill

viernes se le fueron planteando a Zubiri objeciones a su primera obra de madurez, Sobre la esencia (1962), a las que iba respondiendo, y de este modo fue recomponiendo explícita y sistemáticamente la estructura intelectiva que la acompañaba y sostenía.

Me parece que fue en diciembre de 1971 cuando comenzó este Seminario $^{6}$, por iniciativa de la denominada "segunda generación" de discípulos zubirianos, con el propósito de dar coherencia a la primera gran obra de madurez de Zubiri. Las disputas sobre su posible reclusión en un escolasticismo hicieron surgir la necesidad de explicitar las bases gnoseológicas de la metafísica presentada en Sobre la esencia. Así quedó concluido el "núcleo firme" de la filosofía de Zubiri: una nueva idea de la realidad, basada en un análisis del acto de intelección.

Pero, a pesar de este esfuerzo, la obra de Zubiri seguía pareciendo "extemporánea” y todavía se ha hecho más necesario contextualizar su pensamiento e insertarlo en nuestro tiempo ${ }^{7}$. Porque, como indica Pintor Ramos, "desde Sobre la esencia, las publicaciones de Zubiri a primera vista parecen extemporáneas; al no conectar de modo directo con las modas intelectuales de cada momento, aparecían sin contexto explícito, como extraños

6 Debo estos datos a algunos de los participantes en aquellos seminarios, de modo especial a Diego Gracia y a Alfonso López Quintás.

7 Aranguren (1981); Gracia (1983). 
meteoritos caídos de alguna ignota galaxia. Integrar la filosofía de Zubiri en las grandes corrientes de nuestro tiempo, descubrir las raíces que la alimentan y en referencia a las cuales va dibujando su propia trayectoria resulta una labor de gran importancia, para la que Zubiri no ofrece ningún tipo de facilidades" .

Pero lo que está claro es que con la trilogía comienza otra generación que, según Diego Gracia, va a leer a Zubiri desde una nueva perspectiva. Por eso sostiene la siguiente tesis: toda la producción filosófica de Zubiri debe leerse a la luz de la noología, porque es en la trilogía donde alcanza su estado más maduro. A eso se han dedicado principalmente los años ochenta, a entender lo que significa la trilogía; desde esa base cabe esperar que en el futuro se nos abran nuevos horizontes de pensamiento creativo y fecundo.

La Noología obliga, pues, a una contextualización de la filosofía zubiriana. Y más cuando nos encontramos ante la última obra publicada en vida de Zubiri, veinte años después de Sobre la esencia (1962), recibida con gran expectación y que pronto se convirtió para muchos en decepción, pues esperaban otra cosa de aquel filósofo de vida recoleta, apartado de la "Academia" oficial y del mundanal ruido.

En los ambientes de quienes seguían las corrientes más en boga, como la Filosofía analítico-lingüística, el Marxismo, el Estructuralismo, las diversas

8 Pintor Ramos (1993: 68). 
versiones de la filosofía crítica moderna y contemporánea, se desacreditaba a Zubiri, cuya filosofía parecía vulnerable desde los siguientes frentes: 1) se le acusaba de "acriticismo", por cuanto parecía volver a un realismo precrítico, que se consideraba ya superado por el "criticismo" moderno; 2) también era recusable para muchos por permanecer ajena al "giro lingüístico" propiciado por la prevalente filosofía lógico-lingüística; y cabría decir que desvinculada asimismo del —para mí- todavía más importante y radical "giro hermenéutico" contemporáneo; 3) tampoco se aceptaba su desvinculación respecto de una filosofía de la praxis, encaminada a la transformación de la realidad.

Al menos por estas razones (acriticismo, ausencia de análisis lógicolingüístico o hermenéutico, e irrelevancia para la praxis) Zubiri parecía estar al margen de la marcha de la filosofía actual y carecer de repercusión en el pensamiento contemporáneo. Pero, ¿es acertado este juicio tan severo, o más bien la Noología obliga a otra contextualización más positiva?

La trayectoria filosófica de Zubiri ofrece indudablemente elementos de juicio para comprender su última obra y desde ahí superar algunas de las críticas, por ejemplo, la acusación de permanecer ajeno a las corrientes más vivas de la actualidad y la de "acriticismo". Y, en cuanto a la relevancia para la praxis, basta con aludir a la figura de Ignacio Ellacuría (y a un buen número 
de grupos activos en América Latina) para ponderar de otro modo más positivo la capacidad de aplicación social y política de la obra zubiriana9

Una adecuada contextualización, como la ofrecida por Antonio Pintor Ramos y Diego Gracia, sitúa a Zubiri en conexión con la fenomenología como fuente de inspiración para la propia orientación filosófica. Desde el comienzo de su trayectoria Zubiri fue muy consciente del fracaso de la modernidad, debido a que el planteamiento "crítico" moderno conduce al "ideísmo", término que engloba todas las formas de "filosofía de la conciencia" (empiristas, racionalistas e idealistas) que se apoyan en ella para acceder a la realidad, pero que fácilmente conducen a crisis de escepticismo por pretender sustentarse sobre el logos y la razón (sus conceptos e ideas) como si este rodeo permitiera resolver la pérdida del vínculo radical con las cosas y la falta de fundamento en la realidad.

Muchos han interpretado esta crítica zubiriana de la modernidad como una recaída involutiva en el realismo antiguo. Pero Zubiri tampoco acepta la pretendida solución del "realismo" (ni clásico, ni crítico), pues asume el proceso moderno en cuanto desvela el tránsito acrítico del “objeto" a la "realidad" sin justificación y se opone, por consiguiente, a la acrítica identificación del nivel de los objetos con el de la realidad ${ }^{10}$.

9 Ellacuría (1981 y 1994); González (1994).

10 Pintor Ramos (1979). 
Jesús Conill

La Fenomenología de Husserl le permitió situarse en un nuevo nivel filosófico más radical. Por otra parte, también Heidegger y Ortega impulsaron a Zubiri a desvelar las insuficiencias "modernas" pendientes en Husserl y a radicalizar la fenomenología buscando el nivel preconceptual (prejudicativo, prelógico, prerracional) que sea raíz y fundamento de la conciencia, del logos y de la razón.

\section{Noología como transformación de la Fenomenología}

Con el término "noología” Zubiri alude a la investigación acerca de lo que estructural y formalmente es la inteligencia, en concreto, al análisis del acto de intelección sentiente. Este estudio tiene tres partes, en las que se lleva a cabo un análisis de la estructura de la intelección y sus modos: intelección sentiente, logos sentiente y razón sentiente.

La primera parte estudia la intelección, centrándose en los actos de sentir e inteligir como hechos; porque primero se trata de analizar la estructura interna del acto de sentir e inteligir. Y la intelección como acto es un "estar" físico, un acto de aprehensión ("el hecho de que me estoy dando cuenta de algo que me está presente") y no de una facultad (como en la filosofía antigua) ni de la conciencia (como en la filosofía moderna).

Este análisis de la intelección como acto de aprehensión se encamina a determinar la índole esencial constitutiva de la intelección en cuanto tal. No 
un mero concepto general por vía inductiva, sino que lo que busca es la índole constitutiva, esencial y "física" de la intelección. Por eso el análisis ha de llevarnos hasta el modo primario de aprehensión intelectiva, que es la "aprehensión impresiva", para luego determinar los tipos de intelección como "modos" (modalizaciones) de la aprehensión primaria. Los modos ulteriores de la intelección serán el logos y la razón. Por eso, el análisis se centra en los tres momentos estructurales de la impresión: 1) la impresión es afección del sentiente por lo sentido (lo noético); 2) la impresión es la presentación de algo otro: es alteridad en afección (lo noemático) y 3) la fuerza de imposición con que lo presente en mi impresión se impone (lo noérgico) ${ }^{11}$.

El análisis de la alteridad descubre que la afección nos hace presente algo otro "en tanto que otro". Esto otro tiene un contenido, pero tiene también un modo de "quedar" en la impresión. Este modo de quedar, de independencia, es la formalidad. La formalidad no es un concepto metafísico, sino "un momento sentiente de carácter descriptivo".

Y precisamente el análisis de los modos de "formalidad" en impresión da como resultado la distinción entre la aprehensión sensible de estimulidad (sentir estimulidad) y la aprehensión sensible de realidad (sentir realidad). La

11 Desde aquí se trazan los tres capítulos de la noología como filosofía primera, según Diego Gracia, en la segunda parte de su libro Voluntad de verdad: "intelección”, "realidad" y "religación". 
Jesús Conill

aprehensión de realidad sigue siendo sensible (en impresión), pero la nota se aprehende como algo "otro" “en propio", "de suyo". Esta es la formalidad de realidad, descubierta mediante análisis. El sentir es intrínsecamente intelectivo (impresión de realidad). Esta es la impresión primordial de realidad, en la que aprehendemos la formalidad de realidad directa, inmediata y unitariamente, es decir, en y por sí misma. No es conciencia, ni juicio, ni representación, ni siquiera intuición sino acto de aprehensión, un ergon (noergia). Es este un avance respecto a todo dualismo, antiguo y moderno entre sentir e inteligir, al descubrir su unidad estructural; y una superación de la logificación de la inteligencia ${ }^{12}$.

Tras presentar la "estructura formal" de la aprehensión de realidad, Zubiri se pregunta por la "esencia formal" del acto de la intelección sentiente. ¿En qué consiste el "estar presente”? Es actualidad: "estar presente desde sí mismo por ser real" (no es lo mismo que actuidad, que sería un concepto metafísico). En este sentido, la intelección es "actualización impresiva de lo real". Desde aquí se produce un cambio radical en la idea de sensibilidad e inteligencia,

12 Sobre la Noología, además de los trabajos ya reseñados de Diego Gracia y Antonio Pintor, vid. Carpintero (1972-73); Monserrat (1981); Ferraz (1988); Bañón (1999); Mazón (1999); Nicolás (2000). 
pero también en las ideas de realidad y verdad, así como en el modo de entender el despliegue de los ulteriores modos de intelección ${ }^{13}$.

A lo que debemos añadir en este momento que en la aprehensión no sólo hay actos "intelectivos", sino también "sentimientos" y "voliciones". Pues, aunque Zubiri no los ha analizado con la misma detención, son fundamentales para entender la superación zubiriana del intelectualismo ${ }^{14}$.

¿Cuál es el carácter de esta noología zubiriana? ¿Es psicología, lógica, crítica del conocimiento o epistemología? ${ }^{15}$ Zubiri deja bien claro en el Prólogo a Inteligencia sentiente su desacuerdo con el criticismo moderno y su "repulsa de toda crítica del saber como fundamento previo al estudio de lo real". Y, al contrario de lo que a primera vista pudiera parecer, su última obra no debe entenderse como el "fundamento" de su libro anterior Sobre la esencia. Porque, aunque "la investigación sobre la realidad necesita echar mano de alguna conceptuación de lo que sea saber", Zubiri no cree que sea acertado identificar tal necesidad con la anterioridad de un estudio previo acerca de lo que es posible conocer, tal como exige el criticismo. Sencillamente porque la "investigación acerca de las posibilidades de saber" tampoco es posible sin apelar "a alguna conceptuación de la realidad".

13 Para una detallada exposición del desarrollo de la Noología de Zubiri, vid. Conill (1985) y (1986).

14 Vid. Pintor (1993) y (1994). Para su aportación a la ética, vid. Corominas (2000).

15 Conill (1997). 
Jesús Conill

Por consiguiente, el estudio de la realidad contiene afirmaciones sobre la posibilidad del saber y el estudio acerca de las posibilidades del saber engloba conceptos acerca de la realidad. Ello se debe a que "el saber y la realidad son en su misma raíz estricta y rigurosamente congéneres", y a que en el peculiar modo de relacionar saber y realidad por parte de Zubiri no hay prioridad de un lado sobre el otro. La publicación de este estudio noológico representa para Zubiri la mostración de que "el estudio del saber no es anterior al estudio de la realidad" y, por lo tanto, el fracaso de la pretensión criticista momoderna.

Por otra parte, Zubiri matiza que el criticismo moderno no sólo yerra en el aspecto anteriormente contemplado, sino que además se equivoca al instaurarse como Crítica del conocimiento, a menudo denominada “epistemología”; porque considera el conocimiento como si fuera algo primario que reposa sobre sí mismo. Cuando "lo primario del conocimiento está en ser un modo de intelección”. Pero, entonces, la crítica del conocimiento y la epistemología presuponen una "noología”, que no debe confundirse — según Zubiri- con una psicología de la inteligencia, ni con una lógica, sino que trata "de la estructura formal del inteligir".

Esta declaración explícita de anti-criticismo puede volver a decepcionar a aquellos que esperaban de Zubiri una filosofía que no cayera bajo la acusación de acrítica, ajena a la marcha de la filosofía actual. Pero ¿esta crítica zubiriana del criticismo moderno significa que su propuesta de una nueva 
Noología (y desde ahí su filosofía entera) está realmente al margen de los problemas de la filosofía contemporánea?

Sólo una contextualización que estudie la trayectoria intelectual de Zubiri y analice su obra puede servir para comprender la noología, su relación con Sobre la esencia y así superar algunas críticas de las que ha sido objeto. Por ejemplo, si se mantuvo al margen de la filosofía contemporánea, si está justificada la acusación de "acriticismo" o cuál es su verdadero significado, si las esporádicas alusiones al nivel lingüístico (como la significación, el nombre, la frase nominal, la expresión de la intelección racional ${ }^{16}$ permiten reconstruir una analítica del lenguaje dentro de la analítica estructural de la intelección o si esta falta de tratamiento sistemático del lenguaje tiene un cariz polémico frente al panlingüisticismo reinante; o si creía estar aportando el análisis de un nivel más fundamental que el lenguaje.

Esta actitud transcriticista o metacriticista, como respuesta al - tal vezalgo ingenuo criticismo moderno, tiene precedentes muy significativos, como el propio Hegel, aun cuando se trate de una versión y resolución diferentes. Pero también hay otras filosofías contemporáneas que han pretendido llevar adelante la filosofía en forma de "analítica"; alguna incluso ha querido detentar el monopolio de "la Analítica", cuando en realidad han existido diversas formas de filosofía analítica. Ya desde antiguo, por ejemplo, desde Aristóte-

16 Vid., por ejemplo, Pintor-Ramos (1987). 
Jesús Conill

les, pasando por Descartes, Leibniz y Kant, hasta la filosofía contemporánea, donde cabe encontrar sí una analítica lingüística (¡o varias!), pero también analíticas fenomenológicas, existenciarias o existenciales, ontológicas, hermenéuticas... Y, entonces, ¿por qué no puede tener lugar también una analítica noológica dentro de un debate abierto y plantear una "pugna de analíticas"? ${ }^{17}$

\section{De la fenomenología a la metafísica de la persona}

En principio, está clara la conexión de Zubiri con la Fenomenología desde sus primeros escritos académicos, hasta el punto de que la fenomenología puede considerarse como la plataforma desde la que Zubiri orientó su propio quehacer en filosofía, ya que ofrecía un ámbito descriptivo de fenómenos, al margen de cualquier mediación explicativa que distorsionara la manifestación originaria de los datos.

Zubiri repite incansablemente, desde el principio hasta el final de los tres volúmenes de Inteligencia sentiente, que su estudio es un mero análisis de hechos, que no debe confundirse con ninguna construcción teórica, científica o metafísica. En esta pretensión metódica de Zubiri puede descubrirse un enfoque fenomenológico (aunque haya sufrido una peculiar transformación), ya que

17 Vid. Conill (2000: 725 y ss.) 
empieza a filosofar no construyendo una teoría más, sino anteponiendo a toda posible construcción teórica una analítica, capaz de captar la índole formal, esencial y estructural, de los fenómenos y hechos, a través de un análisis descriptivo.

La fenomenología "coloca" ${ }^{18}$ el problema filosófico en la genuina raíz: "desde las cosas" (variando significativamente el lema fenomenológico: "a las cosas mismas"); pero Zubiri aprovechará este nuevo impulso para abrir un camino desde la fenomenología a la metafísica, en la medida en que esta reorientación recupera el horizonte de la realidad superando las mediaciones de la conciencia. Por consiguiente, el nuevo lema será: por la fenomenología a la metafisica. Ahora bien, ¿̇cómo acceder a la realidad desde el fenómeno, cómo pasar fenomenológicamente del objeto a la realidad? ${ }^{19}$

Para resolver este problema (más allá de la objetividad y más allá del ser) Zubiri radicalizó el análisis fenomenológico hasta descubrir que la realidad está dada en un nivel previo a la conciencia y a la relación sujeto-objeto, sin caer en los típicos defectos precríticos. El siguiente texto puede iluminar y acreditar este

18 "Coloca", pero no resuelve ni llega, como es debido, a la metafísica. Recuérdese la anécdota que cuenta Xavier Zubiri (1936): "Hace años, paseando por la carretera de Zumaya, me decía Ortega: 'Lástima de Scheler; no es un metafísico; pasea filosóficamente, eso sí, su retina sobre las cosas; pero nada más'. Por parecida razón jamás le satisfizo como posición última la fenomenología de Husserl”.

19 Vid. Pintor-Ramos (1979). 
Jesús Conill

enfoque acerca del tránsito desde la fenomenología a la metafísica zubirianas: “en el rigor de los términos, el residuo de que nos hablan los fenomenólogos es [...] el momento mismo de realidad. El animal carece de este residuo"20.

La Noología será el desarrollo pormenorizado del análisis de este residuo fenomenológico $^{21}$ : el momento de realidad dado en la sensibilidad humana. El análisis de este dato no es una construcción teórica sino, según Zubiri, un "prolijo y complicado" análisis del acto de intelección sentiente, es decir, de la imimpresión de realidad. La noología desborda el ámbito de la conciencia en el que se centraba la fenomenología husserliana, puesto que supera la dimensión noética de la conciencia, radicalizando el enfoque fenomenológico originario hasta la dimensión noérgica de la intelección como aprehensión impresiva de realidad.

Esta nueva "insistencia analítica" exige una filosofía de la inteligencia (Noología) y una filosofía de la realidad (Metafísica), más fundamental que la ontología de Heidegger y que la filosofía de la vida de Ortega, es decir, otras

20 Zubiri (1966-1967); una presentación de los contenidos fundamentales concernientes a la inteligencia, asumidos en la última obra de Zubiri en que expone su noología, la encontramos ya en el iluminador artículo de Carpintero (1972-73).

21 Contra este carácter residual se ha expresado de diversas maneras Zubiri (1992: 230; 1980: 85), porque ahora el análisis zubiriano de la sensibilidad, de inspiración fenomenológica, no la considera algo residual: "la sensibilidad no [es] una especie de residuo 'hylético' de la conciencia, como dice Husserl, ni un factum brutum, como la llaman Heidegger y Sartre, sino que es un momento intrínseco y formal de la intelección misma”. 
dos vías por las que se ha intentado superar también la fenomenología de Husserl.

Zubiri ha descubierto, a mi juicio, un camino que va desde la fenomenología transformada en forma de noología a una nueva metafísica postnietzscheana ${ }^{22}$ en una época caracterizada como postmetafísica. Como acertadamente indica Pedro Laín, la filosofía de Zubiri constituye un intento de "superación metafísica de la fenomenología de Husserl", al pasar "de la intuición de esencias a la visión de realidades". A diferencia de Heidegger que no rebasa el ámbito de una ontología fenomenológica, Ortega y Zubiri impulsan una nueva línea metafísica desde dos nociones diferentes de realidad, que "son perfectamente conciliables" ${ }^{23}$ dentro de un nuevo programa de metafísica.

También Diego Gracia considera que la filosofía madura de Zubiri tiene por objeto encontrar una salida al método fenomenológico. Para ello Zubiri traslada la indagación fenomenológica desde la "conciencia" (Husserl), la "vida" (Ortega) y la "comprensión” (Heidegger), a la "aprehensión”. Con lo cual, a mi juicio, rebasa la fenomenología de la esencia y la de la existencia (la Analítica hermenéutica), para ofrecer una Analítica noológica del saber de realidad, en la que se parte de la unidad radical y originaria de esencialidad y factualidad.

22 Conill (1988), (1991) y (1997).

23 Laín (1995: 115-116 y 201-202). 
Jesús Conill

A mi juicio, el tránsito desde una fenomenología de la conciencia y desde la hermenéutica de la existencia a una Analítica de la facticidad (como Noología) incorpora el nivel de la facticidad (la formalidad de realidad en la aprehensión), pero sin claudicar ante el giro hermenéutico y su derivación desfundamentadora, por tanto, deja expedito el camino hacia la metafísica desde una instancia a la que prefiero denominar "razón experiencial”"2.

\section{La realidad personal}

El nuevo horizonte metafísico, logrado por Zubiri a través de la transformación de la Fenomenología en Noología, cuenta con una nueva noción de realidad y de esencia a partir del inteligir sentiente ${ }^{25}$. Precisamente en este nuevo horizonte metafísico a partir de una perspectiva noológica — abierta al orden transcendental - es donde hay que situar la noción de realidad personal, por la que se determinará la diferencia esencial del ser humano. Pero esta noción de persona a partir de la Noología zubiriana incorpora la perspectiva del conocimiento científico disponible, especialmente el genético-evolutivo y el neurológico.

24 Conill (1991) y (2006).

25 Vid. Gracia (1986); Pintor-Ramos (1993) y (2006); Ferraz (1988); Gómez Cambres (1983) y (1986). 
Zubiri ha sido un pensador muy atento desde siempre al conocimiento científico y ha tenido una elevadísima valoración de la ciencia moderna. Recordemos que coloca a la ciencia moderna junto a los otros tres productos más gigantescos del espíritu humano (metafísica griega, derecho romano y religión de Israel), equiparándola en grandeza a aquellos tres legados ${ }^{26}$.

La conexión entre filosofía y ciencia se encuentra en Zubiri desde un principio hasta su trilogía sobre Inteligencia sentiente. Recuérdese que en su pensamiento la perspectiva psicofísica que incorpora la dimensión natural del cuerpo humano en la "persona corporal" o en el "cuerpo personal" se remonta a los años treinta, en concreto se encuentra explícita en los estudios titulados “¿Qué es Psicología?" (1935) y "Res cogitans" (1937) ${ }^{27}$, cuyo desarrollo se encuentra en los años cuarenta y cincuenta (véase Sobre el hombre), y posteriormente en los artículos "El hombre, realidad personal” (1963), "El origen del hombre" (1964), "Notas sobre la inteligencia humana" (1967-68) 28 , "El hombre y su cuerpo" (1973), en algunos estudios recogidos en Sobre el sentimiento y la volición; y de modo muy especial en algunos trabajos pioneros sobre la "Actividad cerebral y la actividad intelectiva y opcional", recogidos en Sobre el hombre y que han servido de base al intento de fundamentar bio-

26 Zubiri (1987: 27-57).

27 Recogidos en Zubiri (2002).

28 Vid. el iluminador trabajo de Carpintero (1972-73). 
Jesús Conill

lógicamente la moral por parte de Ignacio Ellacuría en "Biología e inteligencia" (1977) y "Fundamentación biológica de la ética" (1979)². Este intento de fundamentación estaba conectado también con los trabajos sobre "Antropología médica" de Pedro Laín Entralgo y de Diego Gracia, luego proseguidos en el caso de Pedro Laín por una teoría del cuerpo bumano y, en el caso de Diego Gracia, por sus estudios de bioética. Y sin olvidar que esta línea zubiriana de fundamentación de la moral tuvo en la Ética (1958) de José Luis López Aranguren su primer desarrollo y exposición.

Ya desde “¿Qué es psicología?” (1935), al hilo de los Principios de la Psicología fisiológica de Wundt, Zubiri plantea la cuestión de las "dos experiencias, la externa y la interna” y sus correspondientes metodologías ${ }^{30}$. La cuestión básica desde la nueva perspectiva filosófica con la que Zubri pretende superar el idealismo y el positivismo es la que concierne al carácter de la experiencia de los fenómenos de conciencia y consiste en saber si la persona es un "hecho natural". Pues a Zubiri no le parece suficiente comprender la dimensión personal mediante la noción tradicional de substancia, ni tampoco con la de conciencia (como ha sido preponderante en la época moderna), ni acepta situar la cuestión de la persona en relación con el problema cuerpo-alma, sino que más bien hay que separar ambos asuntos, ya que cuerpo y alma sue-

29 Vid. Conill (2010).

30 Zubiri (2002: 247-248). 
len entenderse como dos "res" (en sentido cartesiano), pero la persona es algo distinto ${ }^{31}$.

Para indagar sobre la persona, según Zubiri, hay que preguntarse por el cuerpo, un tema crucial en la filosofía contemporánea, en particular desde Nietzsche $^{32}$, tratado ya por Ortega y Gasset de modo muy significativo ${ }^{33}$, y de gran trascendencia también en el desarrollo de la propia filosofía zubiriana, especialmente por parte de Laín Entralgo ${ }^{34}$. Pero para comprender el cuerpo humano no basta estudiar las facultades psicofísicas del hombre, su "naturaleza”, porque el cuerpo humano no es un cuerpo como lo es un cuerpo físico, sino que "en su realidad concreta es [...] la encarnación de una persona”. Por eso Zubiri llega a afirmar lo siguiente: "yo soy el cuerpo", "yo soy un cuerpo personal", "yo soy una persona corporal" ${ }^{35}$. Ahora bien, el cuerpo humano no puede comprenderse sólo a partir del mecanismo de sus facultades, y por eso Zubiri afirma tajantemente que "la cuestión del ser del hombre jamás podrá ser resuelta por vía naturalista, porque el hombre existe personalmente".

31 Zubiri (2002: 257 y 258).

32 Vid. Conill (1997).

33 Vid., por ejemplo, Ortega y Gasset (2004a: 825) y (2004b: 680-695; Conill (2013).

34 Vid. Laín Entralgo (1989), (1991) y (1995).

35 Zubiri (2002: 297 y 298). 


\section{La persona se funda en la inteligencia}

En los años treinta Zubiri pasa del estudio de la conciencia en la Psicología fisiológica a la corporeidad y en los cuarenta a la inteligencia, por eso me parece que la naturalización de la conciencia, tanto entonces como ahora por su renovada actualidad en las neurociencias ${ }^{36}$, no toca el punto central de la posición zubiriana, que se va a concretar en una nueva concepción de la inteligencia, la cual, aun cuando está basada en el desarrollo del cerebro, sin embargo, no puede ser explicada exclusivamente por vía naturalista, sino que responde a una cuestión más fundamental y es la del puesto del hombre en la naturaleza, en el mundo y en la realidad ${ }^{37}$. A ello contribuyen los estudios de la Antropobiología de la primera parte del siglo XX (Scheler, Gehlen, Plessner, Uexküll, Portmann, Buytendijk), cuyas aportaciones biológicas y las neurológicas ofrecen una base a la innovadora interpretación zubiriana de la inteligencia sentiente ${ }^{38}$, según la cual "todo lo biológico es mental, y todo lo mental es biológico" ${ }^{39}$. Esta concepción de la inteligencia se sustenta en una

36 Vid., por ejemplo, Crick (1994); Edelman y Tononi (2002); Monserrat (2006); Morgado (2012).

37 Vid. Gracia (2013).

38 Vid. Grande Covián (1953) y Rof Carballo (1953) (citados por Diego Gracia, en (2013: nota 49); vid. también Rof Carballo (1952).

39 Zubiri (2006: 53). 
nueva formalización ejercida por el cerebro humano, que Zubiri denomina "hiperformalización" y que es la que permite actualizar las cosas en una nueva formalidad, la formalidad de realidad.

Esta línea de investigación es la que Zubiri va desarrollando en los años cuarenta y cincuenta, exponiéndola en los cursos de esos años, así como en "El problema del hombre" (1959), "El hombre, realidad personal" (1963) y "Notas sobre la inteligencia humana" (1966-67). La inteligencia es la que permite que el hombre esté abierto al mundo, que sea una "esencia abierta" y una "sustantividad" (con independencia del medio y control específico sobre él). Contando con el arsenal de los conocimientos biológicos y los neurológicos de la época (años cuarenta y cincuenta), Zubiri va perfilando su nueva concepción de la inteligencia y llega en su filosofía a comprender al hombre como "animal de realidades" y "animal personal".

Diego Gracia cita el contexto de la lección 29 del curso sobre la libertad, fechada el 5 de mayo de $1952^{40}$, en el que Zubiri expone que la "versión a la realidad" a que nos abre la inteligencia surge por "emergencia" desde las estructuras biológicas del ser humano y que el órgano que ejerce esa innovadora función formalizadora como hiperformalización es el cerebro. Así pues, la primera función de la inteligencia es biológica. Zubiri cuenta con los conocimientos que aportan las ciencias y, a partir de estos conocimientos 
científicos (biológicos y neurológicos), reelabora su filosofía, que conducirá a desarrollar una metafísica de la realidad personal y una noología de la intelección sentiente.

Ya en "El problema del hombre" ${ }^{41}$ expone Zubiri los dos aspectos decisivos para comprender la realidad humana como una sustantividad con inteligencia sentiente, capaz de fundar lo que es la persona, es decir, muestra que la "inteligencia sentiente" que hace del hombre un "animal de realidades" hace de él asimismo [eo ipso] un "animal personal". La noción de persona que Zubiri pone en juego aquí (una lección de 1959, en la que remite a lo expuesto en sus cursos desde 1945$)^{42}$ surge de sus estudios sobre la contraposición de la realidad del hombre con la del animal, pero partiendo de lo que les es común: el hecho de ser seres vivos. La índole esencial de todo ser vivo es la sustantividad biológica del viviente y lo decisivo para diferenciar al hombre del animal no humano está en la "formalidad", es decir, en el modo como las cosas quedan o se actualizan respecto del viviente y que Zubiri correlaciona con diferentes "habitudes". La habitud es una "emergencia" del viviente que

41 Fragmento de la lección 10 del curso "El problema del hombre", impartida el 14 de enero de 1954, en Zubiri (2006: 31-38).

42 Zubiri (2006: 39-63. Fragmento de la 1a lección del ciclo Cuatro lecciones sobre la persona, el 16 de abril de 1959. En esta lección dice Zubiri que presenta conceptos que ha expuesto en sus cursos desde 1945 (Zubiri, 2006: 381, nota 2). 
está dotado de unas estructuras que constituyen su realidad. Zubiri llega a esas habitudes y a las estructuras a partir de las acciones.

Para determinar la habitud radical del hombre, Zubiri parte del estudio del "fenómeno del sentir", de la sensibilidad y del psiquismo animal, en el que distingue entre, por una parte, los receptores y efectores, y, por otra, la función de formalización (que es la que hace posible el incremento de la unidad formal de las estimulaciones). La clave para distinguir al hombre del animal se encuentra en la formalización, cuya función "pende de estructuras nerviosas" y es "fisiológica" ${ }^{43}$.

La función esencial del cerebro consiste en esa formalización por la que se crean las diversas situaciones a las que el animal tiene que responder ${ }^{44}$. Pero, en el caso del hombre, su cerebro se encuentra "hiperformalizado", de manera que el elenco de sus posibles respuestas no está asegurado sino que queda indeterminado. Por ser un animal hiperformalizado, una sustantividad "hiper-animal", el hombre se abre a una función distinta del sentir, la de habérselas con las cosas como realidades, que es lo que constituye la inteli-

43 Zubiri (2006: 49).

44 Los editores de Zubiri (2006: 381, nota referida al texto de p. 51) remiten al libro de Luis Barraquer Bordas (1976: 625-635), en el que se expone la concepción zubiriana del cerebro. Vid. también Barraquer Bordas (1995), con Prólogo de Federico Mayor, en que se expone el estructurismo unicista de Zubiri (desarrollado por P. Laín, I. Ellacuría y D. Gracia) como base para comprender la realidad de la persona humana. 
Jesús Conill

gencia: la capacidad de aprehender las cosas como realidades. La primera función de esta habitud intelectiva es biológica, pero esa misma función nos deja situados en la realidad, sea cual sea su contenido, con lo cual la vida del hombre queda abierta (no enclasada como la animal).

En esta habitud intelectiva hay que considerar al menos dos aspectos muy importantes. Primero, las funciones del cerebro. Pues, aunque "el cerebro no intelige", sí es "el órgano que coloca al hombre en situación de tener que inteligir para poder perdurar biológicamente", para mantenerse en vilo y para perfilar el tipo de intelección. Segundo, la afirmación básica de la unidad estructural entre cerebro e intelección, entre sensibilidad e inteligencia, porque, según Zubiri, "en el hombre, todo lo biológico es mental, y todo lo mental es biológico" 45 .

Este resultado del análisis diferencial entre el animal y el hombre, desde el punto de vista de las habitudes, conduce a Zubiri a plantear el tema de la "unidad estructural" de la sustantividad humana, por la que la actividad intelectiva es nueva. "Contra lo que los neurólogos suelen pensar", "el psiquismo no se adscribe exclusivamente al cerebro ni tan siquiera al sistema nervioso"; "no se trata de que en el sistema nervioso acontezcan unos fenómenos pura-

45 Zubiri (2006: 53). Esta idea recorre toda su obra: vid. también Zubiri (1980) y (1986), con Presentación de Ignacio Ellacuría; Zubiri (2012), con Presentación de Esteban Vargas; asimismo Ellacuría (1979). 
mente biológicos o bioquímicos, y que, al llegar a no se sabe qué regiones 'superiores' del cerebro, surja esa especie de apéndice que sería, por ejemplo, la percepción”" ${ }^{6}$. A juicio de Zubiri, "esto es quimérico", pues se entendería lo psíquico como un mero epifenómeno. Como atinadamente señala Ellacuría, que la compleción de un proceso psico-neural tenga su último eslabón en el cerebro "no significa que sea en el cerebro donde la sensación se produce. La sensación no se produce donde termina el proceso, sino cuando termina el proceso" ${ }^{47}$.

Hace falta otra perspectiva neurocientífica, en la que se comprenda que la función de sentir es un proceso psico-neuronal que envuelve todas las funciones y estructuras bioquímicas y biofísicas del organismo, y que no va adscrita en especial a ninguna de ellas, como no sea en sentido "diferencial". El sistema nervioso no crea la función de sentir, sino que la autonomiza, la desgaja, por diferenciación. De ahí que la función de sentir, en su aspecto psíquico, sea coextensiva a la totalidad de estructuras y procesos biológicos ${ }^{48}$.

\section{Bibliografia empleada}

J. L. Aranguren, El País, 21-1-1981;

J. Arana, La conciencia inexplicada, Madrid, Biblioteca Nueva, 2015.

46 Zubiri (2006: 59).

47 Ellacuría (1979: 331).

48 Zubiri (2006: 60). Vid. Rovaletti (2005) y (2004) y Conill (2015). 
Jesús Conill

J. Bañón, Metafísica y Noología, Salamanca, Universidad Pontificia de Salamanca, 1999.

L. Barraquer Bordas, Neurología fundamental, Barcelona, Toray, 3ª ed., 1976.

L. Barraquer Bordas, El sistema nervioso como un todo. La persona y su enfermedad, Barcelona, Fundació Vidal i Barraquer y Paidós, 1995, con Prólogo de Federico Mayor.

H. Carpintero, "Xavier Zubiri y la doctrina de la inteligencia sentiente", en Exilio, Invierno-Primavera, 1972-73, 61-78.

J. Conill, El crepuisculo de la metafisica, Barcelona, Anthropos, 1988.

J. Conill, El enigma del animal fantástico, Madrid, Tecnos, 1991.

J. Conill, El poder de la mentira. Nietzsche y la politica de la transvaloración, Madrid, Tecnos, 1997, con Prólogo de Pedro Laín Entralgo.

J. Conill, Ética hermenéutica. Crítica desde la facticidad, Madrid, Tecnos, 2006.

J. Conill, "La noología de X. Zubiri”, en Revista de Filosofía, 2a serie, VIII (1985), juliodiciembre, 345-369-

J. Conill, "La filosofía de la inteligencia de X. Zubiri”, en Quaderns de Filosofía i Ciencia, 9/10 (1986), 127-138.

J. Conill, "La fenomenología en Zubiri”, Pensamiento, no 206, mayo-agosto 1997, 177 190.

J. Conill, "Pragmática, Hermenéutica y Noología. Pugna de Analíticas más allá de la Criptometafísica”, en Endoxa, no 12 (2000), 713-731.

J. Conill, "Las líneas de fundamentación en la propuesta ética de Ellacuría", en Ignacio Ellacuría 20 años después, Junta de Andalucía, Sevilla, 2010, 81-92.

J. Conill, "Una cierta lectura hermenéutica de la filosofía orteguiana”, en Zamora (ed.), Guía Comares de Ortega y Gasset, Granada, Comares, 2013, 207-227.

J. Conill, "La realidad personal en perspectiva neurocientífica. La aportación zubiriana", Pensamiento, vol. 76, $\mathrm{n}^{\circ}$ 266, 2015, 253-271.

J. Corominas, Ética primera, Bilbao, Desclée de Brouwer, 2000.

F. Crick, La buisqueda cientifica del alma, Madrid, Debate, 1994. 
G. M. Edelman y G. Tononi, El universo de la conciencia, Barcelona, Crítica, 2002.

A. Diéguez, Transhumanismo. La búsqueda tecnológica del mejoramiento humano, Herder, Barcelona, 2017.

I. Ellacuría, "Biología e inteligencia", Realitas III, 1979, 281-335.

A. Ferraz, Zubiri: el realismo radical, Madrid, Cincel, 1988;

G. Gómez Cambres, La realidad personal, Málaga, Ágora, 1983.

G. Gómez Cambres, La inteligencia bumana, Málaga, Ágora, 1986.

A. González, Un Sólo Mundo, Madrid, Universidad Pontificia Comillas, 1994.

D. Gracia, Voluntad de verdad. Para leer a Zubiri, Barcelona, Labor, 1986; 2a edición, Madrid, Triacastela, 2007.

D. Gracia, El poder de lo real. Leyendo a Zubiri, Madrid, Triacastela, 2017.

D. Gracia, El País, 25-9-1983.

D. Gracia, "El puesto del hombre en la realidad", Cuadernos Salmantinos de Filosofia, 40 (2013), 611-643.

F. Grande Covián, "Zubiri y la biología teórica”, en Homenaje a Xavier Zubiri, Madrid, Alcalá, 1953, 89-101.

P. Laín Entralgo, Cuerpo, alma, persona, Barcelona, Círculo de Lectores, 1995.

P. Laín Entralgo, El cuerpo humano, Madrid, Espasa-Calpe, 1989.

P. Laín Entralgo, Cuerpo y alma, Madrid, Espasa-Calpe, 1991.

P. Laín Entralgo, Alma, cuerpo, persona, Barcelona, Galaxia Gutenberg/Círculo de Lectores, 1995.

M. Mazón, Enfrentamiento y Actualidad, Madrid, Universidad Pontificia Comillas, 1999.

J. Monserrat, "Inteligencia sentiente: un nuevo libro de X. Zubiri", Pensamiento, no 146 (1981), 191-195.

J. Monserrat, "Gerald M. Edelman y su antropología neurológica”, Pensamiento, vol. 62, no 234 (2006), 441-470.

I. Morgado, Cómo percibimos el mundo, Barcelona, Ariel, 2012. 
Jesús Conill

J. Nicolás, "Noología y/o hermenéutica”, en María J. Frápolli-Juan A. Nicolás (eds.), El valor de la verdad, Granada, Comares, 2000, 119-141.

J. Ortega y Gasset, Meditaciones del Quijote (1914), Obras completas, vol. I, Madrid, Taurus, 2004a.

J. Ortega y Gasset, "Sobre la expresión, fenómeno cósmico" (1925), Obras completas, Madrid, Taurus, II, 2004b, 680-695.

A. Pintor-Ramos, "Vigencia de la filosofía de Zubiri”, Diálogo filosófico, 25 (1993), 65-70.

A. Pintor-Ramos, "Zubiri y la Fenomenología”, en Realitas III-IV, 1979, 389-565.

A. Pintor-Ramos, Realidad y sentido, Salamanca, Universidad Pontificia de Salamanca, 1993;

A. Pintor-Ramos, Realidad y verdad, Salamanca, Universidad Pontificia de Salamanca, 1994.

A. Pintor-Ramos, Nudos en la filosofía de Zubiri, Salamanca, Universidad Pontificia de Salamanca, 2006.

A. Pintor-Ramos, "El lenguaje en Zubiri”, Cuadernos salmantinos de Filosofía, 14 (1987), 93-133.

F. Rodríguez Valls, Orígenes del hombre. La singularidad del ser humano, Madrid, Biblioteca Nueva, 2017.

J. Rof Carballo, "Zubiri biólogo", en Homenaje a Xavier Zubiri, Madrid, Alcalá, 1953, 209-225.

J. Rof Carballo, Cerebro interno y mundo emocional, Barcelona, Labor, 1952.

M. Rovaletti, “La génesis primordial el psiquismo: emergencia y formalización”, Vertex. Revista Argentina de Psiquiatría, 2005, vol. XVI, 371-380.

M. Rovaletti, “Morfogénesis, formalización y psico(patología)”, en J. A. Nicolás y O. Barroso (eds.), Balance y perspectivas de la filosofía de X. Zubiri, Granada, Comares, 2004, 529552.

X. Zubiri, El Sol, 8 de marzo de 1936. 
La característica diferencial de los humanos en perspectiva noológica

X. Zubiri, "Notas sobre la inteligencia humana", Asclepio, Madrid, volumen XVIII-XIX, 1966-1967, 341-53.

X. Zubiri, Sobre el sentimiento y la volición, Madrid, Alianza, 1992.

X. Zubiri, Inteligencia sentiente, Madrid, Alianza, 1980.

X. Zubiri, Naturaleza, Historia, Dios, Madrid, Alianza, 1987, 9a ed.

X. Zubiri, Sobre el problema de la filosofía y otros escritos (1932-1944), Madrid, Alianza, 2002, con Presentación de Germán Marquínez Argote.

X. Zubiri, Escritos menores (1953-1983), Madrid, Alianza, 2006, con Presentación de Germán Marquínez y Fideligno Niño.

X. Zubiri, Sobre el hombre, Madrid, Alianza, 1986, con Presentación de Ignacio Ellacuría.

X. Zubiri, El hombre y Dios. Nueva edición, Madrid, Alianza, 2012, con Presentación de Esteban Vargas.

Jesús Conill Sancho

Jesus.Conill@uv.es 
